\title{
Combinação de Grupos Focais e Análise Discriminante: um Método para Tipificação de Sistemas de Produção Agropecuária'
}

Silvia Janine Servidor de Pizzol $^{2}$

Resumo - O objetivo do presente trabalho é apresentar e discutir um método de tipificação de sistemas de produção dividido em duas etapas. $\mathrm{Na}$ primeira foram usados grupos focais e na segunda empregou-se a análise discriminante para validar os resultados obtidos nas entrevistas em grupos. A vantagem deste método é o aproveitamento das impressões de quem interage com os diferentes sistemas de produção (produtores rurais e outros profissionais atuantes na região agrícola estudada) e intuitivamente sabe diferenciá-los. O método foi aplicado na identificação de sistemas de produção de café para a região de Marília, do Estado de São Paulo. Os resultados indicaram a predominância de três sistemas distintos: monocultura de café, cafeicultura e pecuária e pequenas propriedades diversificadas.

Palavras-chaves: grupos focais, tipificação, análise discriminante.

Classificação JEL: R 14

\footnotetext{
${ }^{1}$ Este artigo é parte do trabalho de PIZZOL, S.J.S. Comportamento dos cafeicultores perante o risco: uma análise de três sistemas de produção da região de Marília, SP. Piracicaba, 2002. 150p. Dissertação (Mestrado) - Escola Superior de Agricultura "Luiz de Queiroz”, Universidade de São Paulo.

${ }^{2}$ Engenheira Agrônoma, MSc Economia Aplicada pela ESALQ/USP e doutoranda em Estudios de las Sociedades Latinoamericanas pela Universidade ARCIS - Santiago de Chile. E-mail: silviajanine@yahoo.com.br
} 
Abstract - The objective of the present work is to show and to discuss a method of identification of production systems divided in two stages. In the first one it was used focal groups and in the second the discriminant analysis was used to validate the results gotten in the group interviews. The advantage of this method is the exploitation of the impressions from who interacts with the different production systems (farms and other operating professionals in the studied agricultural region) and intuitively knows how to differentiate them. The method was applied in the identification of production systems of coffee for the region of Marilia of the State of Sao Paulo. The results had indicated the predominance of three distinct systems: "coffee monoculture", "coffee and cattle" and small diversified farm".

Key Words: focal groups, typefication, discriminant analysis.

\section{JEL Classification: $R 14$}

\section{1 - Introdução}

Existem vários trabalhos de identificação de sistemas de produção que se baseiam em variáveis tipificadoras previamente definidas na literatura (Chang \& Sereia, 1980; Fortes, 1981; Payés, 1989; Carmo et al, 2001). No entanto, a tipificação dos sistemas de produção poderia ser enriquecida e adequar-se mais à realidade estudada se tais variáveis fossem definidas a partir de informações cedidas pelos agentes dos sistemas de produção e profissionais atuantes no espaço geográfico estudado. Dessa forma, pode-se fundamentar o estudo nas impressões de quem interage com os diferentes sistemas de produção e intuitivamente sabe diferenciá-los. A metodologia de grupos focais mostra-se adequada para o levantamento desse tipo de informação, pois permite a obtenção de dados mais ricos e detalhados, quando comparada a outros tipos de levantamentos. Para que a identificação dos sistemas de produção tenha fundamentação estatística é interessante que as hipóteses levantadas por intermédio das entrevistas em grupo sejam corroboradas pelo emprego de um método para análise a posteriori de dados, como a análise discriminante.

O objetivo do presente trabalho é apresentar um método de tipificação de sistemas de produção dividido em duas etapas, sendo a primeira fundamentada em grupos focais e a segunda, no emprego da análise 
discriminante para validar os resultados obtidos nas entrevistas em grupos. Descreve-se a aplicação do método na identificação de sistemas produção de café para a região de Marília, do Estado de São Paulo.

\section{2 - Grupos Focais}

Grupo focal é definido na literatura como um tipo especial de entrevista em grupo que tem por objetivo reunir informações detalhadas sobre um tópico particular a partir de um grupo de participantes selecionados. A vantagem da utilização do grupo focal é que os dados revelam mais informações do que os obtidos a partir de outros tipos de levantamentos, tais como as pesquisas individuais. Isto porque os participantes sentem-se livres para revelar a natureza e as origens de suas opiniões sobre um determinado assunto, permitindo que pesquisadores entendam as questões de uma forma mais ampla (Barbour \& Kitzinger, 1999 e Templeton, 1994).

Segundo Barbour \& Kitzinger (1999), o passo mais importante ao se planejar um grupo focal é estabelecer o propósito da sessão. O objetivo tem que ser muito bem definido para que o grupo possa concentrar-se em questões importantes e também para que as pessoas sintam-se encorajadas a participar do processo do início até o fim. As autoras também recomendam que os participantes sejam selecionados dentro de um grupo de indivíduos que convivam com o assunto a ser discutido e que tenham profundo conhecimento dos fatores que afetam os dados mais pertinentes. O tamanho ótimo para um grupo focal é dez a doze membros para que todos possam participar de forma efetiva e a discussão seja bem detalhada.

O grupo focal é conduzido por um moderador, que também tem a função de organizar a pauta da discussão. O papel do moderador é manter a discussão produtiva, garantir que a pauta seja seguida rigorosamente, que todos os participantes exponham suas idéias e impedir a dispersão da questão foco. O moderador nunca deve expor suas opiniões, ou criticar os comentários dos participantes. A discussão deve ser gravada do início ao fim, para facilitar a elaboração do relatório após o encerramento do grupo focal. Entretanto, esse conjunto de dados ricos e complexos pode ser desperdiçado com o emprego de um método 
impróprio de análise.

Frankland \& Bloor (1999) ressaltam a importância da utilização de um método sistemático de análise, o qual inicia-se com a indexação dos relatórios. Esse processo consiste em reunir todos os dados referentes a um tema sob um cabeçalho, de forma que o material torne-se facilmente manejável para os propósitos da análise. A seguir é apresentado um exemplo do processo de indexação em um trecho da transcrição do grupo focal realizado no município de Garça:

Produtor 1: eu vejo 2 tipos de agricultores: 1 altamente capitalizado, que não depende exclusivamente de recursos da própria agricultura, tecnificado e muito em cima da cafeicultura. E o agricultor que sobrevive com recursos da própria agricultura. Esse agricultor possui uma série de limitações, trabalhando com uma escala menor, seriam os pequenos e médios agricultores. Eles desenvolvem também cafeicultura, mas não tecnificada, como o capitalista.

Produtor 2 Eu vejo na região produtores bem tecnificados, focados na cafeicultura e muitos produtores buscando alternativas, diversificação de culturas. Mais voltados para culturas permanentes, em função dos problemas de topografia, tipos de solo. Portanto, buscando culturas permanentes para a diversificação.

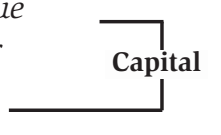

Produtor 4: Em Garça é muito difícil fazer uma agricultura alternativa para café. Em Garça, Gália, Marília, na região é muito difícil sair da cafeicultura. Os cafeicultores estão muito bem tecnificados. Não só o grande produtor. O pequeno pode não usar maquinário, mas ele usa tecnificação em função de tratos culturais e tem muita gente com alta produtividade.
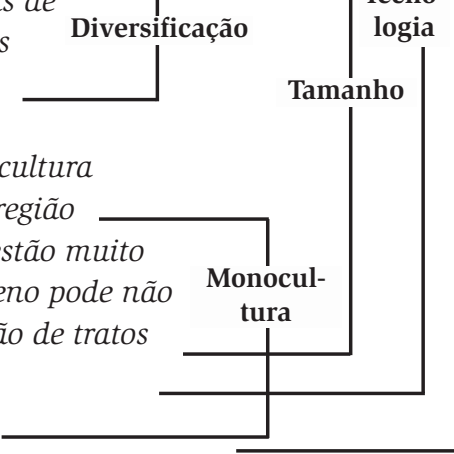

Os mesmos autores recomendam a utilização do método indutivo de análise sistemática, cujo objetivo é derivar proposições que se aplicam de forma geral a todos os dados. A generalidade das proposições é alcançada focando-se nos "casos de desvio", isto é, nos itens indexados que contradizem a proposição analítica. Devido a isso, a análise indutiva também é chamada de análise dos casos de desvio.

Para realizar a interpretação dos dados, o analista deve modificar a 
proposição original, incluindo os casos de desvio. Por exemplo: “todos os produtores estão endividados e enfrentam dificuldades para aplicar tecnologia de ponta em suas atividades, exceto os que possuem uma fonte de renda não agrícola". De uma maneira alternativa, os casos de desvio podem ser eliminados modificando a definição da população à qual a proposição analítica aplica-se. Por exemplo, pode-se encontrar que todas as exceções à proposição "todos os produtores estão endividados e enfrentam dificuldades para aplicar tecnologia de ponta em suas atividades, exceto os que possuem uma fonte de renda não agrícola" vêm de grandes monocultores de café. Portanto a proposição original deve ser restrita aos pequenos e médios agricultores e aos grandes produtores que não cultivam café. A vantagem da concentração nos "casos de desvio" é a revisão das proposições e definições, evitando a perda de dados. Além disso, a necessidade de eliminar todos os "casos de desvio" é um estímulo para estender a análise, impedindo seu encerramento prematuro.

\section{3 - Análise Discriminante}

A análise discriminante é uma técnica para tratamento a posteriori de dados, isto é, visando a validação de hipóteses levantadas a partir de outros métodos (por exemplo, grupos focais). Para isto, dados quantitativos são levantados através de surveys ou outras técnicas estatísticas. Segundo Rencher (1995), a análise discriminante visa maximizar a diferença entre as médias dos grupos estudados, conforme descrito na equação (1):

$$
\lambda=\frac{\mathbf{a}^{\prime} \mathbf{H} \mathbf{a}}{\mathbf{a}^{\prime} \mathbf{E} \mathbf{a}}
$$

onde a matriz $\mathrm{H}$ é definida como:

$$
\mathbf{H}=\mathrm{n} \sum_{i=1}^{k}\left(\mathbf{y}_{\mathrm{i}} \cdot-\mathbf{y}_{. .}\right)\left(\mathbf{y}_{\mathrm{i} .}-\mathbf{y}_{.}\right)^{\prime}=\sum_{i=1}^{n} \frac{1}{n} \mathbf{y}_{\mathrm{i} .} \mathbf{y}_{\mathrm{i} .}-\frac{1}{k n} \mathbf{y}_{. .} \mathbf{y}_{. .},
$$


e a matriz E:

$$
\mathbf{E}=\sum_{i=1}^{k} \sum_{j=1}^{n}\left(\mathbf{y}_{\mathrm{ij}}-\mathbf{y}_{\mathrm{i} .}\right)\left(\mathbf{y}_{\mathrm{ij} .}-\mathbf{y}_{\mathrm{i}}\right)=\sum_{i j} \mathbf{y}_{\mathrm{ij} .} \mathbf{y}_{\mathrm{ij}}{ }^{\prime}-\sum_{i} \frac{1}{n} \mathbf{y}_{\mathrm{i} .} \mathbf{y}_{\mathrm{i} .},
$$

onde $\mathbf{y}_{\mathrm{ij}}$ são vetores que representam amostras $\mathrm{j}$ das populações $\mathrm{i}$ e cada vetor contêm medidas de p variáveis; a é o vetor característico cujos elementos são os coeficientes procurados de cada uma das funções discriminantes lineares e $\lambda$ é a raiz característica da função discriminante.

Rencher (1995) esclarece que a matriz H possui dimensão $p \times p$ e sua diagonal principal é composta pela soma de quadrados "entre grupos" para cada uma das $p$ variáveis. A matriz $\mathbf{E}$ também possui dimensão $p x$ $p$ e sua diagonal principal é composta pela soma de quadrados "dentro dos grupos” para cada variável. É importante destacar que a soma de quadrados "dentro dos grupos" é uma boa medida da homogeneidade dos mesmos e a soma de quadrados “entre grupos” refere-se à diferença entre as médias dos grupos. Sendo assim, o objetivo da equação (1) é obter o $\lambda$ que maximiza a razão soma de quadrados "entre grupos" /soma de quadrados "dentro dos grupos", atingindo, desta forma, a máxima discriminação entre os grupos.

Além da separação de grupos, a análise discriminante também é aplicada para classificar, de maneira eficiente, os indivíduos dentro dos grupos estudados. Sharma (1996) descreve vários métodos de classificação (valor de corte, teoria da decisão estatística, função de classificação e distância de Mahalanobis), sendo que o método da teoria da decisão estatística foi o utilizado neste trabalho. Este método baseiase na teoria Bayesiana e consiste em minimizar os erros de classificações incorretas levando em consideração as probabilidades prévias e os custos de classificação incorreta. Sua principal vantagem é que não pressupõe probabilidades prévias e custos de classificação incorreta iguais, o que a torna um dos métodos de classificação mais gerais. Para o caso de dois grupos, o método da teoria de decisão estatística designa uma observação para o grupo 1 se: 


$$
Z \geq \frac{\bar{Z}_{1}+\bar{Z}_{2}}{2}+\ln \left[\frac{p_{2} C(1 / 2)}{p_{1} C(2 / 1)}\right]
$$

e uma observação é classificada no grupo 2 se:

$$
Z<\frac{\bar{Z}_{1}+\bar{Z}_{2}}{2}+\ln \left[\frac{p_{2} C(1 / 2)}{p_{1} C(2 / 1)}\right]
$$

onde $\mathrm{Z}$ é o escore discriminante para uma dada observação, $Z_{\mathrm{j}}$ é o escore discriminante médio para o grupo $\mathrm{j}, \mathrm{p}_{\mathrm{j}}$ é a probabilidade prévia do grupo j e C(i/j) é o custo de classificação incorreta dentro do grupo i de uma observação que pertence ao grupo j.

\section{4 - Procedimento Metodológico}

O objetivo dos grupos focais realizados no Escritório de Desenvolvimento Rural de Marília foi identificar sistemas de produção de café. Para definir o número de grupos focais necessários, o EDR de Marília foi dividido em sub-regiões caracterizadas por deterem uma exploração agropecuária predominante. Esta divisão foi baseada nas estatísticas do Instituto de Economia Agrícola e no conhecimento empírico dos engenheiros agrônomos da Coordenadoria de Assistência Técnica Integral - CATI Regional Marília. Desta forma, foram obtidas quatro sub-regiões onde predominam cafeicultura, pecuária extensiva, pequena e média propriedades diversificadas e plasticultura, conforme ilustrado na Figura 1.

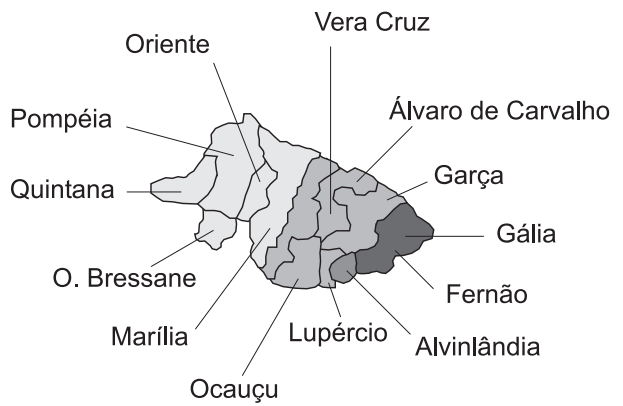

Pequenas propriedades diversificadas Plasticultura Cafeicultura

Pecuária Extensiva

Figura 1 - Atividades agropecuárias predominantes nas sub-regiões do EDR de Marília 
Os participantes dos grupos focais, bem como os locais das entrevistas foram escolhidos com o auxílio dos técnicos da CATI Regional Marília. Procurou-se selecionar agricultores e outros profissionais ligados à agricultura com amplo conhecimento do tipo de exploração agropecuária praticado na região. Ao todo, foram realizados cinco grupos focais, distribuídos entre os municípios de Garça, Alvinlândia, Marília e Oscar Bressane.

A análise discriminante foi aplicada para referendar os resultados obtidos na primeira etapa do levantamento. Com base nas informações obtidas nos grupos focais sobre variáveis tipificadoras e características gerais dos diferentes sistemas foi formulado um questionário aplicado em entrevistas individuais com 109 agricultores da região. Esses agricultores foram pré-classificados nos sistemas de produção sugeridos pelos resultados dos grupos focais, com base nas atividades desenvolvidas nas propriedades.

A seleção dos produtores rurais entrevistados foi aleatória, com base nas listas de associados fornecidas pela AFRUVEC e Cooperativa dos Cafeicultores de Garça - GARCAFÉ. Foram selecionados agricultores apenas dos municípios de Álvaro de Carvalho, Alvinlândia, Gália, Garça, Fernão, Lupércio, Ocauçu e Vera Cruz, por serem as cidades com maior concentração de propriedades cafeicultoras. É válido ressaltar que o número de propriedades rurais selecionadas pode ser considerado significativo, uma vez que corresponde a aproximadamente $11 \%$ do total de unidades de produção de café dos municípios acima especificados, segundo informações da Secretaria de Agricultura e Abastecimento do Estado de São Paulo.

O objetivo das entrevistas individuais foi de atribuir valores às seguintes variáveis pré-selecionadas:

$\mathrm{X} 1$ : área da propriedade (ha);

X2: participação da renda da principal atividade agropecuária no total da receita bruta da propriedade (\%);

X3: número de trabalhadores familiares;

X4: número de trabalhadores assalariados;

X5: valor do último financiamento através do crédito rural convencional (R\$);

X6: valor do último financiamento obtido através de CPR, troca de produtos por insumos, ou através da cooperativa $(\mathrm{R} \$)$; 
X7: valor da renda não agrícola (R\$/mês);

X8: valor do capital proveniente de fonte não agrícola aplicado na propriedade (R\$/mês);

X9: área da propriedade em que são realizados tratos mecanizados (ha);

X10: estado de conservação das máquinas e implementos agrícolas existentes na propriedade (nota de 1 a 10);

X11: estado de conservação das benfeitorias existentes na propriedade (nota de 1 a 10);

X12: valor médio gasto anualmente com defensivos e fertilizantes (R \$/ano)

X13: área da propriedade em que são realizadas práticas conservacionistas (\%);

X14: número de anos que reside na zona urbana;

X15: número de anos que a propriedade pertence à família;

X16: \% de membros da família com curso superior, ou cursando faculdade e X17: avaliação dos benefícios trazidos pela participação em cooperativas, sindicatos e associações (nota de 1 a 10).

As variáveis acima descritas foram submetidas à análise discriminante para classificar as propriedades selecionadas dentro dos respectivos grupos e explicar as diferenças existentes entre os mesmos. A análise estatística foi realizada no programa SAS e os resultados obtidos são apresentados a seguir.

\section{5 - Resultados e Discussão}

A análise dos grupos focais revelou a existência de cinco sistemas de exploração agropecuária na região de Marília: (i) monocultura de café; (ii) pequena e média propriedade diversificada; (iii) cafeicultura e pecuária; (iv) pecuária extensiva e (v) pequena propriedade leiteira diversificada.

A monocultura de café, embora presente em todo o EDR de Marília, é predominante nos municípios de Garça, Gália, Vera Cruz, Fernão, Lupércio e Alvinlândia. Esse tipo de exploração é realizado por dois tipos de agricultores: a) o proprietário de até 100 alqueires, que geralmente trabalha com mão-de-obra familiar (não exclusiva), cuja única fonte de renda é a agricultura e depende de financiamento bancário para manter a atividade, por isso está descapitalizado; b) o proprietário que tem uma atividade não agrícola como principal fonte de receita, 
geralmente com áreas superiores a 100 alqueires, onde não há mão-deobra familiar. Este tipo de produtor não depende do crédito agrícola e está constantemente injetando recursos provenientes de atividades não agrícolas na cafeicultura, por isso trabalha com tecnologia de ponta, incluindo maquinário.

O desinteresse dos monocultores em diversificar suas propriedades, inclusive dos descapitalizados, ficou evidente durante as entrevistas. Mesmo tendo enfrentado algumas fases de preços baixos do ciclo plurianual do café, os produtores insistem em afirmar que qualquer tentativa de diversificação não terá sucesso e apenas causará prejuízo. As tentativas de diversificação com as culturas do cacau, seringueira e mesmo algumas frutas, realizadas a partir da década de 60, foram lembradas com desprezo, como se pode observar no comentário: " $a$ melhor alternativa para a cafeicultura, que eu via na época, era café”. Tais comentários esclarecem que a cafeicultura é uma atividade que continuará tendo grande importância para a região, pois dificilmente será abandonada pelos produtores rurais.

A facilidade de acesso à tecnologia de produção de café também contribui muito para a existência da monocultura. Todos os produtores estão constantemente informados sobre as novas técnicas de aplicação de defensivos e fertilizantes, novas variedades e sistemas de plantio que geram maiores produtividades. Há vários veículos de difusão das tecnologias, entre eles as cooperativas, a CATI, empresas de insumos e os próprios cafeicultores. Os produtores mais capitalizados e interessados estão freqüentemente inovando suas técnicas de produção e mesmo os menores, apesar de não utilizarem tecnologia de ponta, também buscam inovar dentro de seus limites, para atingir maiores produtividades.

Para os monocultores a cafeicultura é sinônimo de segurança na comercialização e facilidade de crédito. Alguns comentários ratificam essa afirmação:

“(...) todas as outras tentativas de fruticultura não lhe garantem segurança em termos de mercado. O café dá uma estabilidade para o produtor. Essa que é a grande vantagem. Você produz, guarda, você pode se endividar, fazer o que quiser, mas se sente seguro em termos de produção";

"O potencial da região é o café, porque não tem outra coisa. Não tem 
uma usina que beneficia soja, milho, não têm posto para levar para o CEASA à parte de olericultura. Todo mundo está voltado para o café".

"A cafeicultura tem mais facilidade ao crédito. Não diretamente ao banco, mas através do processo de cooperativa e das próprias firmas. Então, para comprar um insumo ele te financia. Não precisa ir ao banco, que tem aquela série de impedimentos, que não deixam que você tenha acesso (...)".

Outro sistema de produção, também muito comum na região, é o da pequena e média propriedade diversificada. Nessas propriedades há a presença da cafeicultura e de outras atividades, como a plasticultura no município de Alvinlândia, a sericicultura em Gália e a fruticultura em todo o EDR. A diversificação é realizada principalmente com culturas permanentes, em função da topografia e do tipo de solo da região, que não permite revolvimento constante. Nessas propriedades é comum a presença da mão-de-obra familiar, embora não exclusivamente, e da adoção do sistema de parceria, como forma de reduzir os custos de produção. Geralmente, é um sistema de produção com baixa mecanização. Além disso, os proprietários estão descapitalizados, pois vivem exclusivamente da agricultura, o que explica a falta de tecnologia de ponta e de investimentos na propriedade.

A análise dos grupos focais deixa claro que a maioria dos pequenos e médios produtores está constantemente buscando novas alternativas de cultivo, pois dependem disso para sobreviver. Com base nos comentários dos agricultores supõe-se que a renda proveniente da monocultura desenvolvida em pequena escala não é suficiente para sustentar a família do produtor e muito menos para manter sua propriedade, o que favorece o crescimento do êxodo rural. Muitas pequenas propriedades estão transformando-se em loteamentos de chácaras, zonas de lazer, e outras estão sendo englobadas por grandes propriedades. Os seguintes trechos extraídos dos grupos focais subsidiam essa afirmação:

"Os pequenos produtores não conseguem renda. Está havendo uma substituição desses pequenos proprietários. Alguns que estão lá são aqueles que ainda, por raiz de família, tentam manter a propriedade. Uma luta até com patrimônio de família, mas com dificuldade de sobrevivência. Mas não tem renda, apesar de aplicar tecnologia”.

"O pequeno proprietário, fundo de Gália e Fernão, tem uma 
propriedade, que não aufere nem renda para sobrevivência, são subassalariados".

"O grande tabu hoje é a diversificação, porque o pequeno não pode sobreviver de monocultura. Apenas um tropeço e entra em falência".

Também existe, embora em menor freqüência, o sistema de produção que combina cafeicultura e pecuária, esta sendo uma atividade secundária, com baixa produtividade e aplicação de tecnologia, apenas para aproveitar áreas inaptas ao cultivo do café. O comportamento dos produtores que atuam nesse sistema é semelhante ao dos monocultores de café, pois a cafeicultura é sua principal fonte de receita.

O sistema de produção pecuária extensiva, desenvolvida em grandes propriedades, é predominante nos municípios de Marília, Oscar Bressani e Pompéia, embora também exista com menor freqüência na região cafeicultora. Grande parte dos pecuaristas da região não realiza investimentos em melhoramento genético e manejo de pastagens, o que resulta em uma atividade com baixa tecnificação, caracterizada por baixo número de unidades animais por hectare e pastagens degradadas.

É freqüente o sistema da pequena propriedade leiteira diversificada, onde está presente a mão-de-obra familiar, embora não exclusivamente. Apesar da pecuária leiteira proporcione um baixo nível de renda aos produtores, ela é interessante pela liquidez diária de receita. Esses pequenos pecuaristas diversificam a atividade principalmente com a fruticultura, sendo comum o arrendamento de pastagens degradadas para expandir o cultivo de frutas, visando o aumento de renda.

Uma vez que o objetivo da pesquisa é a identificação dos sistemas de produção de café, a análise discriminante apenas foi aplicada para os sistemas em que a cafeicultura está presente, isto é, os monocultores, os pequenos agricultores de produção diversificada e os produtores que associam a cafeicultura e a pecuária.

A significância estatística das variáveis consideradas na análise discriminante foi analisada inicialmente por um teste $\mathrm{F}$ univariado, onde os três grupos foram comparados separadamente para cada variável. Os resultados demonstram que, para um nível de significância de $5 \%$, as variáveis que quantificam a participação da renda da principal atividade agropecuária no total da receita bruta da propriedade, o tipo de mãode-obra utilizado (familiar ou assalariada), o consumo de defensivos e 
fertilizantes, o número de anos em que o agricultor reside na zona urbana e a participação do mesmo em cooperativas, associações e sindicatos contribuíram para a separação dos sistemas de produção (Tabela 1). É válido comentar que no trabalho de Payés (1989) variáveis referentes ao tipo de mão-de-obra utilizada e os pesos relativos das atividades agropecuárias na renda da propriedade também foram importantes fatores de tipificação de sistemas.

Tabela 1. Teste de significância univariado para as variáveis consideradas na análise discriminante

\begin{tabular}{|c|c|c|}
\hline Variável & $\begin{array}{l}\text { Valor } \\
\text { de F }\end{array}$ & $\begin{array}{l}\text { Probabilidade } \\
\quad>\mathrm{F}\end{array}$ \\
\hline $\mathrm{X}_{1}=$ área da propriedade & 0,87 & 0,4236 \\
\hline $\begin{array}{l}\mathrm{X}_{2}=\text { participação da renda da principal atividade } \\
\text { agropecuária no total da receita bruta da propriedade }\end{array}$ & $83,63^{*}$ & $<0,0001$ \\
\hline $\mathrm{X}_{3}=$ número de trabalhadores familiares & $6,45^{*}$ & 0,0023 \\
\hline $\mathrm{X}_{4}=$ número de trabalhadores assalariados & $3,71^{*}$ & 0,0276 \\
\hline $\begin{array}{l}\mathrm{X}_{5}=\text { valor do último financiamento através do crédito } \\
\text { rural convencional }\end{array}$ & 1,70 & 0,1876 \\
\hline $\begin{array}{l}\mathrm{X}_{6}=\text { valor do último financiamento via CPR, troca de } \\
\text { produtos por insumos, ou através da cooperativa }\end{array}$ & 1,56 & 0,2142 \\
\hline $\mathrm{X}_{7}=$ valor da renda não agrícola & 0,14 & 0,8686 \\
\hline $\begin{array}{l}\mathrm{X}_{8}=\text { valor do capital proveniente de fonte não } \\
\text { agrícola aplicado na propriedade }\end{array}$ & 1,07 & 0,3475 \\
\hline $\begin{array}{l}\mathrm{X}_{9}=\text { área da propriedade em que são realizados } \\
\text { tratos mecanizados }\end{array}$ & 1,44 & 0,2407 \\
\hline $\begin{array}{l}\mathrm{X}_{10}=\text { estado de conservação das máquinas e } \\
\text { implementos agrícolas existentes na propriedade }\end{array}$ & 1,16 & 0,3189 \\
\hline $\begin{array}{l}\mathrm{X}_{11}=\text { estado de conservação das benfeitorias } \\
\text { existentes na propriedade }\end{array}$ & 0,32 & 0,7288 \\
\hline $\begin{array}{l}\mathrm{X}_{12}=\text { valor médio gasto anualmente com defensivos } \\
\text { e fertilizantes }\end{array}$ & $4,19 *$ & 0,0178 \\
\hline $\begin{array}{l}\mathrm{X}_{13}=\text { área da propriedade em que são realizadas } \\
\text { práticas conservacionistas }\end{array}$ & 0,03 & 0,9706 \\
\hline $\mathrm{X}_{14}=$ número de anos que reside na zona urbana & $3,81^{*}$ & 0,0252 \\
\hline $\begin{array}{l}\mathrm{X}_{15}=\text { número de anos que a propriedade pertence à } \\
\text { família }\end{array}$ & 1,03 & 0,3623 \\
\hline $\begin{array}{l}\mathrm{X}_{16}=\text { número de membros da família com curso } \\
\text { superior, ou cursando faculdade }\end{array}$ & 0,60 & 0,5502 \\
\hline $\begin{array}{l}\mathrm{X}_{17}=\text { avaliação dos benefícios trazidos pela } \\
\text { participação em cooperativas, sindicatos e associações }\end{array}$ & $3,25^{*}$ & 0,0427 \\
\hline
\end{tabular}

Fonte: Resultados de pesquisa ${ }^{*}$ Indica significância estatística até $5 \%$ 
Embora os resultados do teste $\mathrm{F}$ univariado indiquem que apenas seis variáveis foram significativas a $5 \%$, os testes que medem a significância global da análise, isto é, $\Lambda$ de Wilks e sua aproximação de $\mathrm{F}$, demonstram que a análise realizada com as 17 variáveis foi significativa a 0,01\% (Tabela 2).

Tabela 2. Resultados dos testes multivariados Wilk's Lambda e sua aproximação de F

\begin{tabular}{c|c|c|c}
\hline Teste & Valor & Valor de F & Probabilidade > F \\
\hline Wilk's Lambda & 0,2489 & 5,32 & 0,0001 \\
\hline
\end{tabular}

Fonte: Resultados de pesquisa

No presente trabalho não se optou pela utilização de métodos stepwise $e^{3}$ de análise discriminante, porque as 17 variáveis foram selecionadas com base no conhecimento e vivência de agricultores, lideranças rurais e profissionais ligados à agricultura da região de Marília. Desta forma, não seria interessante descartar grande parte dessas variáveis com base em critério puramente estatístico, pois levaria à perda de ricas informações coletadas nos grupos focais, que certamente contribuem para a separação dos sistemas de produção, conforme demonstrado pelos testes de significância global.

Visto que a análise discriminante global foi estatisticamente significante, funções discriminantes foram estimadas para descrever as diferenças entre os grupos. A partir dos dados levantados, foram ajustadas três funções discriminantes, sendo uma para cada sistema de produção, respectivamente, monocultura de café (Z1), cafeicultura e pecuária (Z2) e propriedades diversificadas (Z3).

$\mathrm{Z}_{1}=-76,86+0,013 \mathrm{X}_{1}+1,296 \mathrm{X}_{2}-1,176 \mathrm{X}_{3}-0,246 \mathrm{X}_{4}-0,00006 \mathrm{X}_{5}+$ $0,00016 X_{6}+0,000022 X_{7}-0,00025 X_{8}+0,165 X_{9}-0,32 X_{10}+1,0163 X_{11}$ $-0,00000675 X_{12}+0,01521 X_{13}+0,00151 X_{14}+0,139 X_{15}--0,00941 X_{16}$ $+0,1613 X_{17}$

$\mathrm{Z}_{2}=-53,607+0,0118 \mathrm{X}_{1}+1,053 \mathrm{X}_{2}-1,1123 \mathrm{X}_{3}-0,2174 \mathrm{X}_{4}-0,00004 \mathrm{X}_{5}$ $+0,00011 X_{6}+0,000007 X_{7}-0,00015 X_{8}+0,127 X_{9}+0,0067 X_{10}+$

\footnotetext{
${ }^{3}$ A descrição detalhada dos métodos de seleção de variáveis na análise discriminante (all subsets, stepwise selection, forward selection, backward elimination) pode ser obtida em Sharma (1996) e Rencher (1995).
} 
$0,9337 \mathrm{X}_{11}-0,00000177 \mathrm{X}_{12}+0,0217 \mathrm{X}_{13}+0,00311 \mathrm{X}_{14}+0,1153 \mathrm{X}_{15}-$ $0,0103 \mathrm{X}_{16}+0,1615 \mathrm{X}_{17}$

$Z_{3}=-45,809+0,00953 X_{1}+0,933 X_{2}-0,2059 X_{3}-0,1945 X_{4}-0,000045 X_{5}$

$+0,000104 X_{6}-0,0000197 X_{7}-0,000032 X_{8}+0,14 X_{9}-0,075 X_{10}+$ $1,1387 \mathrm{X}_{11}-0,0000149 \mathrm{X}_{12}+0,0165 \mathrm{X}_{13}-0,0061 \mathrm{X}_{14}+0,113 \mathrm{X}_{15}+-$ $0,00926 \mathrm{X}_{16}+0,0188 \mathrm{X}_{17}$

Os valores das raízes características indicam que uma função discriminante foi suficiente para descrever a maior parte da separação entre os grupos, pois a primeira raiz característica $\left(\lambda_{1}\right)$ representa uma elevada proporção em relação ao total $\left(\lambda_{1}+\lambda_{2}\right)$, de cerca de $90,35 \%$ (Tabela 3).

Tabela 3 - Valor e proporção das raízes características

\begin{tabular}{c|c|c}
\hline Raiz Característica & Valor & Proporção \\
\hline$\lambda_{1}$ & 2,2408 & $90,35 \%$ \\
\hline$\lambda_{2}$ & 0,2393 & $9,65 \%$ \\
\hline
\end{tabular}

Fonte: Resultados de pesquisa

Os valores das variáveis foram normalizados, portando foi possível aferir a contribuição relativa das mesmas na separação dos grupos. Considerando a função discriminante $Z_{1}$, nota-se que as variáveis X2 e $\mathrm{X} 3$, justamente as que apresentaram maiores valores de $\mathrm{F}$, foram as que mais contribuíram para a separação dos grupos, pois seus coeficientes são os maiores, em termos absolutos. Ou seja, a participação da principal atividade na renda total da propriedade e a utilização de mãode-obra familiar no estabelecimento tiveram o maior peso na tipificação dos sistemas de produção. É importante ressaltar que essas variáveis também foram importantes para a tipificação dos sistemas estudados por Payés (1989). No trabalho de Fortes (1981), a utilização de mãode-obra familiar foi uma das variáveis que contribuíram muito para a discriminação de um dos grupos de propriedades rurais analisados.

A Tabela 4 contém informações sobre a classificação das observações dentro dos respectivos grupos. 
Combinação de Grupos Focais e Análise Discriminante:

um Método para Tipificação de Sistemas de Produção Agropecuária

Tabela 4. Classificação das propriedades rurais dentro dos sistemas de produção da região de Marília

\begin{tabular}{|c|c|c|c|c|}
\hline \multirow[b]{2}{*}{$\begin{array}{c}\text { Classificação } \\
\text { Atual }\end{array}$} & \multirow[b]{2}{*}{$\begin{array}{l}\text { Número de } \\
\text { Observações }\end{array}$} & \multicolumn{3}{|c|}{ Classificação segundo Análise Discriminante } \\
\hline & & Monocultura & $\begin{array}{c}\text { Cafeicultura e } \\
\text { Pecuária }\end{array}$ & $\begin{array}{l}\text { Propriedade } \\
\text { Diversificada }\end{array}$ \\
\hline Monocultura & 39 & 37 & 1 & 1 \\
\hline $\begin{array}{l}\text { Cafeicultura e } \\
\text { Pecuária }\end{array}$ & 28 & 3 & 22 & 3 \\
\hline $\begin{array}{l}\text { Propriedade } \\
\text { Diversificada }\end{array}$ & 42 & 2 & 7 & 33 \\
\hline \multicolumn{4}{|c|}{ Taxa aparente de classificação correta } & $84,4 \%$ \\
\hline \multicolumn{4}{|c|}{ Taxa de erro aparente } & $15,6 \%$ \\
\hline
\end{tabular}

Fonte: Resultados de pesquisa

Os resultados demonstram que $84,4 \%$ das propriedades rurais foram classificadas corretamente nos respectivos sistemas de produção. Das 39 observações pré-classificadas no grupo de monocultores, 37 foram mantidas e 2 foram realocadas para o grupo cafeicultura e pecuária e para o dos diversificados. Desta forma, aproximadamente $95 \%$ dos monocultores foram classificados corretamente, o que pode ser considerado um bom resultado. Para os dois sistemas de produção restantes (cafeicultura e pecuária e propriedades diversificadas) a separação foi mais difícil, pois a proporção de classificação correta foi de 78,6\%. Das 28 propriedades pré-classificadas no sistema cafeicultura e pecuária, 22 foram mantidas no respectivo grupo, sendo que 3 foram transferidas para o grupo dos monocultores e 3 para o dos agricultores diversificados. No sistema de produção da propriedade diversificada, foram classificadas corretamente 33 observações, de um total de 42 , pois 2 foram realocadas para o grupo dos monocultores e 7 para o dos cafeicultores e pecuaristas. Não obstante, a taxa aparente de classificação correta pode ser considerada elevada, o que demonstra a eficiência do modelo utilizado para separar os sistemas de produção agropecuária da região de Marília.

\section{6 - Considerações Finais}

O método utilizado no presente trabalho para identificação de sistemas de produção, a partir de grupos focais e posterior validação 
das informações através da análise discriminante, foi satisfatório para a identificação dos sistemas de produção agropecuária da região de Marília. Na realidade, a validade da metodologia adotada deve-se, principalmente, ao embasamento das hipóteses sobre a agricultura regional no conhecimento empírico de agricultores, líderes rurais e profissionais ligados à agropecuária do EDR de Marília, o que contribuiu para minimizar o erro na identificação dos sistemas de produção.

Por outro lado, algumas deficiências na mensuração das variáveis devem ser apontadas. Em primeiro lugar, deve-se citar a dificuldade enfrentada para obter a amostra de agricultores a serem entrevistados, pois não foi possível acessar uma listagem completa das propriedades existentes na região de Marília, contendo informações sobre as atividades desenvolvidas, área e localização, o que dificultou a obtenção de uma amostra não viesada. O único órgão que poderia ceder essas informações é a Secretaria de Agricultura e Abastecimento do Estado de São Paulo, que por motivos legais não pode tornar público seu cadastro de produtores rurais. Desta forma, o universo de propriedades ficou restrito às informações cedidas pela AFRUVEC e GARCAFÉ.

Também é importante citar que parte dos produtores entrevistados mostrou-se reticente em responder algumas perguntas do questionário, principalmente àquelas referentes à renda, e também enfrentou dificuldades para informar alguns dados técnicos, como área em que são efetuados tratos culturais mecanizados e consumo de defensivos e fertilizantes. Essas dificuldades refletem a falta de planejamento e controle contábil na propriedade e podem ter contribuído para o elevado desvio padrão e obtenção dos valores não significativos de F para grande parte das variáveis discriminantes.

Apesar das dificuldades enfrentadas na quantificação das variáveis, o objetivo da pesquisa foi atingido e identificou-se a monocultura de café, o sistema que combina cafeicultura e pecuária e o da pequena e média propriedade diversificada como sistemas predominantes na região cafeicultora do EDR de Marília. Por fim, ressalta-se que a seleção de um método de tipificação de sistemas de produção deve levar em consideração, em primeiro lugar, a finalidade da pesquisa. O método descrito neste trabalho possui grande utilidade para pesquisas que visem a modelagem matemática de sistemas de exploração agropecuária 
e para a definição de estratégias de desenvolvimento regional, dadas à riqueza e detalhamento dos dados proporcionados pelos grupos focais.

\section{7 - Referências Bibliográficas}

BARBOUR, R.S.; KITZINGER, J. Developing focus group research. London: Sage, 1999. 225p.

CARMO, M.S.; OLIVEIRA, J.T.A; ZARONI; M.M.H. Métodos de tipificação de agricultores voltados ao desenvolvimento rural sustentável. Agricultura em São Paulo, SP, v.48, t.1, p.1-10, 2001.

CHANG M.Y.; SEREIA, V.J. Tipificação e caracterização dos produtores rurais do Estado do Paraná. Boletim Técnico IAPAR, n.39, p.5-151, maio 1980.

FORTES, N.T. Tipificação de estabelecimentos agropecuários e a programação de extensão rural. Viçosa, 1981. 130p. Tese (Doutorado) - Universidade Federal de Viçosa.

FRANKLAND, J.; BLOOR, M. Some issues arising in the systematic analysis of focus group materials. In: BARBOUR, R.S.; KITZINGER, J. (Ed.). Developing focus group research. London: Sage, 1999. Chap.10, p.156-172.

PAYÉS, M.A.M. Sistemas de produção predominantes no município de Rio Azul - Paraná. Boletim Técnico IAPAR, n.27, p.5-43, set. 1989.

RENCHER, A.C. Methods of multivariate analysis. New York: John Wiley \& Sons, 1995. 627p.

SHARMA, S. Applied multivariate techniques. New York: John Wiley \& Sons, 1996. 493p.

TEMPLETON, J.F. Focus groups: a strategic guide to organizing, conducting and analyzing the focus group interview. New York: McGraw-Hill, 1994. 308p. 